\title{
COMMUNICATION SKILLS FOR MENTORS IN SOCIAL BUSINESS
}

\author{
Gilberto Marzano \\ Ecoistituto Udine, Italy \\ Rezekne Academy of Technologies, Latvia \\ Simone Zorzi \\ Ecoistituto del Friuli Venezia Giulia, Italy
}

\begin{abstract}
The word mentor comes from "Mentor", the old man to whom Odysseus entrusted his house and son Telemachus. Accordingly, mentoring can be assumed as the guidance whereby one person shares their experience and expertise to support other people to progress in their own lives and careers.

Mentoring encompasses supportive relationships finalized to job performance, leadership practices, a career as well as teaching learning-processes.

This paper analyzes the function of mentors in social business and the communication skills they need in using digital media.

This paper aims to give an overview of the various aspects and issues related to social mentoring, focusing on the use of digital communication technologies to assist mentors in providing guidance, knowledge, and support.

It reports and discusses the preliminary results of the desk research carried out by the authors within the EU project DICCMEM.
\end{abstract}

Keywords: social mentoring, social mentors, digital communication skills, digital social mentoring, mentee.

\section{Introduction}

The word mentor comes from Ancient Greek and means "of the mind". "Mentor" was the old man to whom Odysseus entrusted his house and son Telemachus.

Mentoring is usually defined as a relationship between a mentor and a protégé. The mentor is an older, more experienced person, who helps a younger and less experienced protégé in developing their career (Megginson, 2006).

It is broadly agreed that a mentor is outside the protégé's chain of supervision.

Mentoring is an umbrella term, often opened to various interpretations, that encompasses formal or informal supporting, guiding, coaching, teaching, role modeling, counseling, advocating, and networking (Haggard, Dougherty, 
Turban, \& Wilbanks, 2011). It has been identified as a supportive activity in various contexts, such as business corporations, schools, universities, and hospitals. (Hansford, Tennent, \& Ehrich, 2002).

Mentoring has emerged as a key policy intervention in a wide range of contexts, from business enterprise, education, health and social care, and employment.

In the last decades, business mentoring and mentoring in business raised its popularity. Business mentoring is an organizational phenomenon involving a triad relationship (mentor, protégé, organization).

Business mentoring programs are, today, increasingly prevalent and research is growing around the world (Clutterbuck, Kochan, Lunsford, Domínguez, \& Haddock-Millar, 2017; Ehrich \& Kimber, 2016; Kumar, 2018; Omonijo, 2019; Zvaigzne \& Kotane, 2019).

The opposite of business mentoring is social mentoring, which promotes and supports the mentees for social inclusion.

This paper aims to give an overview of the various aspects and issues related to social mentoring. It focuses on the use of digital communication technologies to assist social mentors in providing guidance, knowledge, and support.

\section{The objective of the DICCMEM project}

The research is conducted within the project DICCMEM (Development and Introduction of a Communication Competencies Model for Enhancing and Maintaining a Business Mentor Network), a 24-month Erasmus plus Strategic Partnership project that involves six partners from five countries (Latvia, Italy, Lithuania, Poland, and Bulgaria).

The aim of the DICCMEM project is to analyze the issues affecting communication in business mentoring and, at the same time, propose solutions to overcome them.

More in detail, DICCMEM will examine the effectiveness of mentoring focusing on communication dynamics that take place among mentor, protégé, and organization in order to reduce the impacts due to the ongoing changes that the digital revolution is imposing in every sector of human life.

The growing interest in social business and social innovation persuaded us to extend our analysis, including social mentoring.

\section{Research methodology}

In this paper, we report the preliminary results coming from a desk analysis. In carrying out our desk research, we followed the recommendations 
made by the Preferred Reporting Items for Systematic Reviews and MetaAnalyses (PRISMA) group (Moher, Liberati, Tetzlaff, Altman, \& Prisma Group, 2009), whilst also considering the methodology adopted in some recent reviews in the e-mentoring field (Chong et al., 2019; Neely, Cotton, \& Neely, 2017).

In order to extract relevant research from the published literature, a systematic literature search was undertaken between January $1^{\text {st }} 2015$ and September $30^{\text {th }}$ 2019. From this, we collected a large number of significant articles published in Scopus and ISI Web of Science conference proceedings, as well as in the databases of leading world publishers such as WileyOnline and SAGE. We also used Google Scholar in order to integrate the results obtained and evaluate the popularity of articles, taking account of their citations. Over the last few years, Google Scholar has grown to become a highly scholarly database and has become competitive with other databases such as ISI Web of Science and Scopus (Harzing, 2013; Harzing \& Alakangas, 2017). We only dealt with international peer-reviewed publications (journal articles and transactions).

The process of identifying and reviewing the literature was conducted in two phases. In the first phase, carried out between May 2019 and July 2019, we searched for relevant articles by adopting a simple search criterion, collecting articles that, in their title, abstract, or list of keywords, contained the terms "mentoring" or "mentors" as well as "business mentoring" and "social mentoring". We then analyzed the abstracts of the collected articles, eliminating items that were inconsistent or that referred to overly generic issues. Finally, we obtained a collection of 168 articles that we analyzed, taking into account:

- Empirical or theoretical results

- Reliable experimentation

- Technological architecture

- Applicability

In the next paragraphs, we highlight the notion of social mentoring as emerged from the literature analysis and shortly report some aspects related to social mentoring.

\section{Social mentoring}

In 2003, the pilot project called "Navigating Health in the Community" (NHIC) initiated to investigate the gaps and opportunities in the Brighton \& Hove area for mentoring services for people with Asperger's syndrome. This project opened the research on social mentoring.

The term "social mentoring'" was coined by Gill, the NHIC coordinator, to emphasize the centrality of the socialization process in developing mentoring practices (Gill \& Jones, 2005). 
The NHIC project indicated that training workshops and coaching for social workers is advantageous and increases their socialization skills.

From a literature review conducted in 2007, a preponderance emerged of the use of the term mentor (734) over the term social mentoring (0) with befriending registering a significant presence (37) (Social Mentoring Research Group, 2007).

It has been noted that, in the UK, befriending is "an approach which is synonymous with mentoring in that itis based on a dyadic attachment relationship" (Social Mentoring Research Group, 2007).

However, before the introduction of the term social mentoring, it was popular the term psycho-social mentoring to designate a mentor's activity to give encouragement, advice and feedback, as well as an enhanced sense of competence, effectiveness and clarity of identity (Kram, 1983).

Social mentoring and business mentoring share the same central idea that the 'relationship' plays an important role in facilitating learning. Mentoring should provide the professional or the personal development of the mentee (Carruthers, 1993). Mentoring is a dynamic activity, and the form it takes within a social setting influences its potential for success or failure as a developmental intervention.

Accordingly, social mentoring should help people involved in social activities to discover what sort of person they are and how they can acquire the behavior appropriated to their role.

A mentor should be at the same time a consultant, a counselor, and a Cheerleader, but not a supervisor.

\section{Some preliminary results}

In our research, it emerged immediately the very limited number of studies in social mentoring (25 selected articles) respect business mentoring (143 selected articles).

We found that social mentoring initiatives are especially developed to support social integration and employment of disadvantaged and marginalized groups (Prieto-Flores \& Gelis, 2018), including migrant integration (Bagnoli \& Estache, 2019) and assisting migrant to work (De Cuyper, Vandermeerschen, \& Purkayastha, 2019). Over the last few years, many social e-mentoring applications to support newcomer migrants and refugees have been implemented (Benton \& Glennie, 2016).

E-mentoring encompasses computer-mediated and mutually beneficial relationships between a mentor and a protégé. 
However, from our literature analysis no evidence is emerged on the effectiveness of social mentoring, although there is broad consensus about its importance.

Nevertheless, the analysis done has shown better the issues related to social mentoring and the use of digital communication to support integration and empowerment processes. Most of articles on social mentoring underline the potential of digital technology to enhance mentoring process.

E-mentoring can expand the social and professional network of protégés, offer access to online resources and job opportunities as well as increase interpersonal communication (Ponum, Samad, \& Ramzan, 2018).

Although our research is at the beginning, it shows that social mentoring can be an essential component of the social inclusion process. For instance, it can provide personalized support to long-term unemployed people or socially disadvantaged and marginalized groups.

Figure 1 shows the key mentor competences as emerged from our literature analysis.

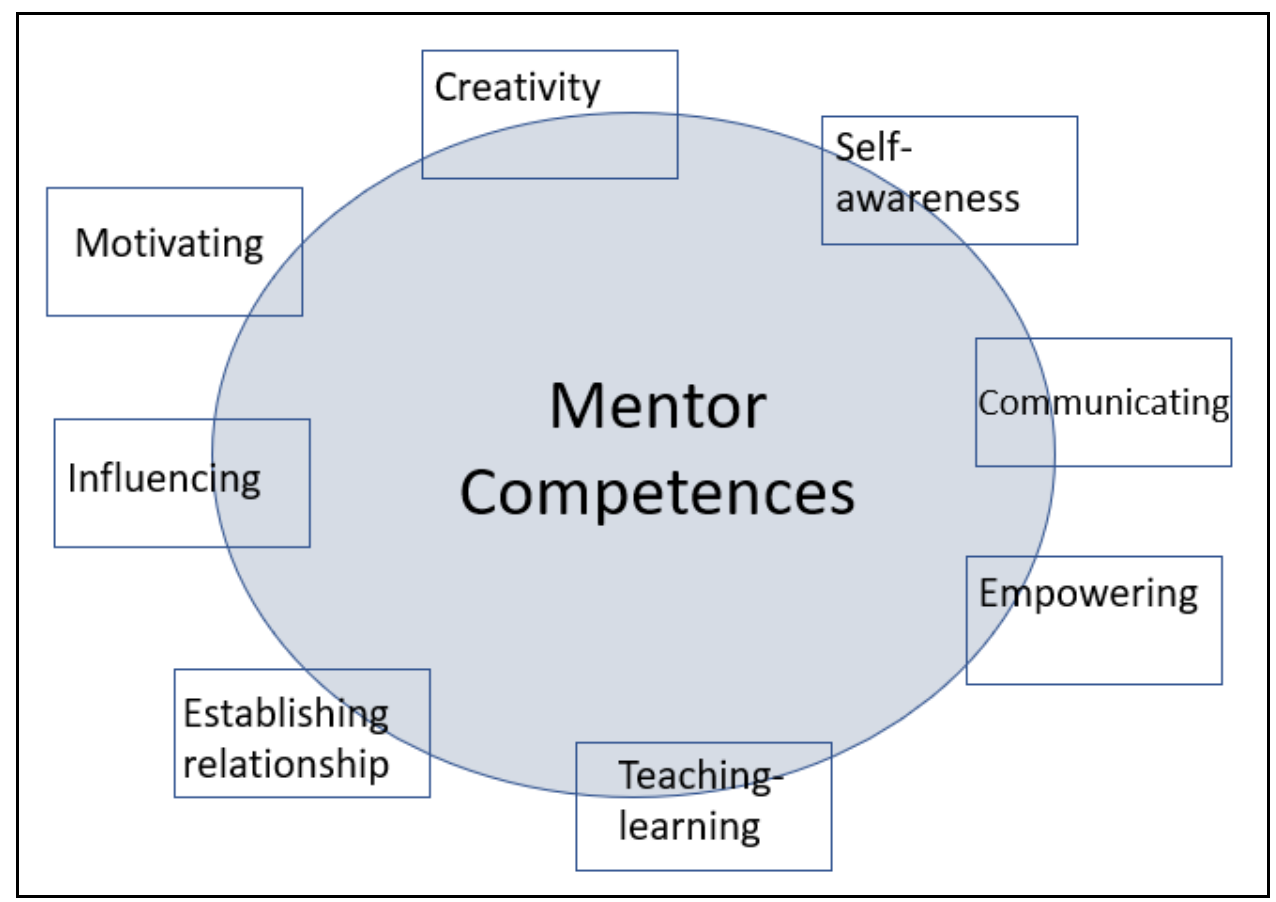

Figure 1 Key mentor competences (own source)

However, the above are transversal competences. Mentors should know the domain in which they should carry out their business.

Accordingly, social mentors should have specific competences and skills in the sector of their mentees. They should know the mentees' needs, habits, and behavior. 
The context of mentees can impact communication processes. Depending on the particular characteristics of mentees, specific communication strategies should be provided. Moreover, in social mentoring, it might be necessary to adopt personalized strategies. This is the case of social mentoring of people with Autism Spectrum Disorders.

Digital technology can be very useful to implement new mentoring strategies and to extend the mentors' activity.

\section{Conclusion}

Face-to-face mentoring is the most common form of mentoring.

However, our literature analysis evidenced that new types of mentoring, such as virtual mentoring, e-mentoring or online mentoring, have emerged and can enhance the mentoring opportunities.

The potential of digital technology is enormous and allows for the creation of new mentoring programs. Especially mentees belonging to disadvantaged and marginalized groups can benefit. In this regard, social mentors can take advantages from the digital technology, creating new opportunities for mentoring relationships.

However, a research effort is needed. Virtual mentoring is becoming more popular in practice, but research on this form of mentoring has not kept pace.

Moreover, there are technological issues that should be considered. Privacy concerns are negatively related to e-mentoring adoption rates and maintenance of e-mentoring relationships.

In this paper, we highlighted that social mentoring is a quite unexplored field but with enormous potential.

Finally, from our preliminary research emerges that digital technology can generate changes in the scope of mentoring, making new things possible, but, at the same time, introducing new issues and challenges.

To find appropriate solutions to mentoring in the digital era, we ought to know how to use the technology available in innovative ways.

\section{Acknowledgments}

This paper has been supported by the Erasmus plus Strategic Partnership project DICCMEM (Development and Introduction of a Communication Competencies Model for Enhancing and Maintaining a Business Mentor Network). The views expressed reflect those of the authors alone. 


\section{References}

Bagnoli, L., \& Estache, A. (2019). Mentoring labor market integration of migrants: Policy insights from a survey of mentoring theory and practice (No. 2019-15). ULB-Universite Libre de Bruxelles.

Benton, M., \& Glennie, A. (2016). Digital Humanitarianism: How tech entrepreneurs are supporting refugee integration. Migration Policy Institute.

Carruthers, J. (2003). The principles and practice of mentoring. In Caldwell, B., Carter, E.M. (Eds.), The return of the mentor (pp. 17-52). Routledge.

Chong, J.Y., Ching, A.H., Renganathan, Y., Lim, W.Q., Toh, Y.P., Mason, S., \& Krishna, L.K. (2019). Enhancing mentoring experiences through e-mentoring: a systematic scoping review of e-mentoring programs between 2000 and 2017. Advances in Health Sciences Education, 1-32.

Clutterbuck, D.A., Kochan, F.K., Lunsford, L., Domínguez, N., \& Haddock-Millar, J. (Eds.). (2017). The SAGE handbook of mentoring. Sage.

De Cuyper, P., Vandermeerschen, H., \& Purkayastha, D. (2019). Migrant mentoring to work: defining an old-but-innovative instrument. International Journal of Evidence Based Coaching and Mentoring, 17(2), 108-121.

Ehrich, L.C., \& Kimber, M. (2016). The purpose and place of mentoring for women managers in organisations: an australian perspective. In Handbook on well-being of working women (225-241). Springer, Dordrecht.

Gill, K.S., \& Jones, A. (2005). Navigating health in the community, University of Brighton.

Haggard, D.L., Dougherty, T.W., Turban, D.B., \& Wilbanks, J.E. (2011). Who is a mentor? A review of evolving definitions and implications for research. Journal of management, 37(1), 280-304.

Hansford, B., Tennent, L., \& Ehrich, L.C. (2002). Business mentoring: help or hindrance? Mentoring and tutoring, 10(2), 101-115.

Harzing, A.W. (2013). A preliminary test of Google Scholar as a source for citation data: a longitudinal study of Nobel Prize winners. Scientometrics, 94(3), 1057-1075.

Harzing, A.W., \& Alakangas, S. (2017). Microsoft Academic: is the phoenix getting wings? Scientometrics, 110(1), 371-383.

Kram, K.E. (1983). 'Phases of the mentor relationship', Academy of Management Journal, 26, 608-625.

Kumar, P. (Ed.). (2018). Exploring dynamic mentoring models in India. Springer International Publishing.

Megginson, D. (2006). Mentoring in action: A practical guide. Development and Learning in Organizations: An International Journal, 20(5).

Moher, D., Liberati, A., Tetzlaff, J., Altman, D.G., \& Prisma Group. (2009). Preferred reporting items for systematic reviews and meta-analyses: the PRISMA statement. PLoS medicine, 6(7). Retrieved from

http://journals.plos.org/plosmedicine/article?id=10.1371/journal.pmed.1000097

Neely, A.R., Cotton, J., \& Neely, A.D. (2017). E-mentoring: A model and review of the literature. AIS Transactions on Human-Computer Interaction, 9(3), 220-242.

Omonijo, D.O., Adetola, O.B., Lawal, A.S., Anyaegbunam, M.C., Odukoya, J.A., \& Olowookere, E.I. (2019). An Exploratory Study of Igbo Business Mentoring (Nwa Boy) for Establishing Small-Scale Enterprise: Panacea to Youth Unemployment in South-East Geo-Political Zone of Nigeria. The Journal of Social Sciences Research, 5(4), 1103-1115. 
Ponum, M., Samad, S., \& Ramzan, R. (2018). E-Mentoring. In Mentorship Strategies in Teacher Education (112-135). IGI Global.

Prieto-Flores, Ò., \& Gelis, J.F. (2018). What type of impact could social mentoring programs have? An exploration of the existing assessments and a proposal of an analytical framework. Pedagogía Social. Revista Interuniversitaria, 31, 153-167.

Social Mentoring Research Group. (2007). Towards an understanding of Mentoring, Social Mentoring and Befriending (Practice Briefing Paper). Brighton: University of Brighton/Equal Brighton and Hove. Retrieved from file://C:/Users/gilma/AppData/ Local/Temp/SocialMentoringBristol.pdf, last accessed 01.19.2020

Zvaigzne, A., \& Kotane, I. (2019). Mentoring as one of the Prerequisites for the Development of the Entrepreneurial Environment. In Proceedings of the 12th International Scientific and Practical Conference, Volume I, 363. 